\begin{tabular}{|c|c|}
\hline ISSN $214996-628$ & \\
\hline $\begin{array}{c}\text { TOURISM } \\
\text { AND } \\
\text { MANAGEMENT } \\
\text { AN INTERNATIONLL JOURNAL }\end{array}$ & $\begin{array}{l}\text { Journal of Tourism\&Management Research } \\
\text { ISSN: } 2149-6528 \\
2020 \text { Vol. 5, Issue.2 } \\
\text { http://ottomanjournal.com/index.html }\end{array}$ \\
\hline
\end{tabular}

\title{
Conceptualization Research of Travel Comfort: A preliminary Study
}

\author{
Abstract \\ The comfort that tourists feel during their journey deeply affects the quality of tourism. \\ However, the definition and connotation of travel comfort still need to be clarified. Therefore, \\ this study uses the in-depth interviews method to sample 9 research participants, including 3 \\ senior tourism experts and scholars, 3 experienced tourists, and 3 tourism industry \\ practitioners. The content analysis method was used for coding and analysis. The results of \\ this study divide travel comfort into five areas: environment, travel content, travel destination, \\ personal feelings and partnerships, and 20 sub-projects. This article not fully attempts to \\ conceptualize travel comfort only, but also points out how the practice can be applied, and \\ finally puts forward future research suggestions. \\ Keywords: Travel comfort, conceptualization, qualitative research, tourists, travel, China \\ JEL Classification: G41, L83, Z32 \\ Submitted:11/05/2020; Accepted:14/08/2020 \\ You-Yu Dai, Associate Professor. (Corresponding Author). International Business School of \\ Shandong Jiaotong University, No. 1508 Hexing Rd., Shuangdao Bay for Science and Technology \\ Town, Weihai City, Shandong Province, China. Tel.+86(631)3998925 \\ Email: psyyyt@gmail.com \\ Xiuyuan Zhang, Master of Business Administration. China-ASEAN International College of Dhurakij \\ Pundit University, 110/1-4 Prachachuen Rd., Laksi, Bangkok 10210 Thailand. \\ Email: 632349023@qq.com \\ Xiaonan Feng, Lecturer. International Business School of Shandong Jiaotong University, \\ No. 1508 Hexing Rd., Shuangdao Bay for Science and Technology Town, Weihai City, Shandong \\ Province, China. \\ Email: 201164@sdjtu.edu.cn
}




\section{Introduction}

The tourism industry is in a period of vigorous development, and the entire tourism market is in great demand. The GDP contribution rate of up to $10 \%$ reflects the huge scale of the tourism market (WTTC, 2017). While gaining self-development, the tourism industry should pay more attention to service quality, hardware facilities, and comfort in tourism in order to meet the fiercely competitive market and achieve healthy and rapid development. Therefore, the rapid development of the tourism industry also makes people pay more attention to the quality of service, convenience, comfort experience in tourism. Now the tourism industry is changing from a seller's market to a buyer's market, with service as the guide to deal with the increasingly competitive tourism market. A well-developed tourism industry and a begin competitive market will ultimately benefit consumers and tourism industry personnel (Dai, 2018).

In the past studies, there was little research on travel comfort, and there was a gap in theory. Li and Tang (2013) believed that the concept of travel comfort includes comfort, healthy transportation, food and accommodation environment, beautiful natural environment, and warm service during the tour. Zhou, Sun and Geng (2012) believed that human comfort is an index to evaluate human comfort in different climate environments. Human comfort is affected by weather and climate factors. Peng and Wang (2014) suggested that theoretically, realism can make tourists feel comfortable. Yang (2008) proposed to evaluate travel comfort with comprehensive indicators, including the satisfaction of tourists' physiological needs, the satisfaction of tourists' psychological needs, the satisfaction of local public needs and the comfort of tourist destinations. Wang (2015) used climate (temperature, humidity, wind chill) and environment (noise, atmospheric environment) to evaluate the comfort of the tourism environment.

Tourism activities are essentially a process of human selection, experience and experience of geographic space. Different travel experiences directly affect tourists' decisions and behaviors. In recent years, with the continuous development of the tourism industry, competition in the source market has intensified (Fang, 2008). With the upsurge of tourism development, the concepts of "comfortable tourism climate", "comfortable tourism environment", and "comfortable tourism service" in tourism are beginning to receive widespread attention. However, the current research on travel comfort mainly focuses on aspects such as tourism climate comfort, and the method is still based on the analysis of the local climate.

In summary, the authors of the current research believe that the connotation of travel comfort still needs to be clarified, the definitions have not been consistent, and there is no consistent statement on its operational definition. Most scholars describe it from the external environment, and do not fully involve physical and psychological comfort. Therefore, this study intends to further conceptualize the components and connotation of travel comfort based on the past researchers' concept of travel comfort. The purpose is to solve the following two problems: (1) What is the concept of travel comfort? (2) What are the components of travel comfort? This research period attempts to fill the gap in the academic theory of travel comfort.

\section{Literature Review}

With the rapid development of tourism, travel comfort is inevitably mentioned. Comfortable feeling is the instinctive requirement of people, and the pursuit of a suitable climate is one of the important motives for people to travel. Yang (2015) believed that travel comfort refers to the degree of satisfaction physiologically and psychologically obtained by tourists during the journey. Travel comfort reflects the value of tourism environment and becomes an important part of the attraction of tourist destinations. Li and Tang (2013) believed that travel comfort 
refers to the degree of satisfaction that tourists acquire physically and psychologically during the journey.

At present, some scholars only elaborate on climate, destination, service, entertainment, surroundings, etc. The research direction is relatively simple. For example, Ye et al. (2012) believed that travel comfort can be explained by describing the comprehensive impact indicators of temperature and humidity on the human body. At present, no scholars have clearly defined the concept of travel comfort, but travel comfort is frequently used by tourists and travel agencies. Scholars have constantly called for a clearer definition of the concept of travel comfort in academic circles (Liu et al., 2019; Wang et al., 2015; Yang, 2015).

In recent years, research on travel comfort has gradually increased. The research on travel comfort started late, and the research content and results have developed. At the same time, it can still be seen that the research on travel comfort can be improved. The researchers mainly explored tourism climate comfort (Liu et al., 2019; Ma, 2019), tourism environment comfort (Qin et al., 2014; Wang et al., 2015), destination comfort (Li \& Tang, 2013; Liu et al., 2019) and other aspects. Among them, scholars choose climate comfort more for research, and believe that the temperature and humidity index, wind chill, clothing index, and precipitation in the climate factor are important factors affecting travel comfort (Hua et al., 2014; Jiao et al., 2018). Other scholars have studied the impact of destination image, air quality, noise decibels, and warmth of services on travel comfort.

The definition of academic travel comfort is inconsistent, and there is not yet a complete and accurate definition. This study summarizes the connotation of travel comfort that many researchers unanimously agree from the literature and defines it as: travel comfort is a sense of being human, and it is the psychological and physiological satisfaction with the external environment. Climatic factors are the main factors affecting travel comfort, but there are many other factors that affect travel comfort.

The attributes of travel comfort are academically diverse and complex. This researcher tried to classify the attributes of "travel comfort" in order to conveniently summarize the dimensions of travel comfort. There are few articles titled "Travel Comfort" on China National Knowledge Internet (CNKI), which is the focus of this research review. The current status of this research also confirms the importance of this research. This researcher sorts the attributes of past literature on travel comfort according to dimensions as shown in Table 1.

Table 1: Research dimensions of travel comfort.

\begin{tabular}{ccc}
\hline Author & Dimension & Attribute \\
\hline \multirow{2}{*}{ Liu et al. (2019) } & climate & Season, weather, sunny and rainy \\
\cline { 2 - 3 } & environment & Tourism acoustic environment, traffic noise \\
\cline { 2 - 3 } & scenic area & Tourist capacity, crowding degree, tourist distribution density \\
\hline \multirow{2}{*}{ Jiao et al. (2018) } & climate & Air temperature, relative humidity, wind speed, sunshine \\
\cline { 2 - 3 } & Tourism suitability & Clothing index \\
\hline Xu (2017) & Wind environment & Pedestrian zone wind speed \\
\cline { 2 - 3 } & Thermal & Sun radiation \\
& environment & \\
\hline
\end{tabular}




\begin{tabular}{|c|c|c|}
\hline \multirow{5}{*}{ Wang et al. (2015) } & meteorological & Temperature, relative humidity \\
\hline & air quality & Carbon dioxide, carbon monoxide \\
\hline & Acoustic & \\
\hline & & noise \\
\hline & environment & \\
\hline \multirow[b]{2}{*}{ Qin et al. (2014) } & environment & Ecological environment, air quality, water quality conditions \\
\hline & climate & $\begin{array}{l}\text { Annual and monthly average temperature, relative humidity, } \\
\text { cloud distribution, sunshine wind speed, rainfall }\end{array}$ \\
\hline \multirow{4}{*}{ Li and Tang (2013) } & Natural & \\
\hline & environment & Landscape resources, climate, ecological environment \\
\hline & cultural & Tourism transportation, tourism accommodation, \\
\hline & environment & environmental sanitation, scenic area management \\
\hline
\end{tabular}

\section{Methodolgy}

\subsection{Data Analysis}

This study uses content analysis, which is a systematic technique for analyzing and processing message content. This analysis method can display content externally for objective and systematic measurement and description (Lin, 2008). The main value of the content analysis method is to categorize the content in a systematic, objective and quantitative way, and to narrate and explain according to the statistics of these categories (Huang, 2014). The analysis unit of the content analysis method can be words, symbols, topics, sentences or paragraphs, items, etc. The content of interviews in this study is mainly based on narrative, so this study uses sentences and paragraphs as the unit of analysis, and finally categorizes them into four categories as shown in Figure 1.

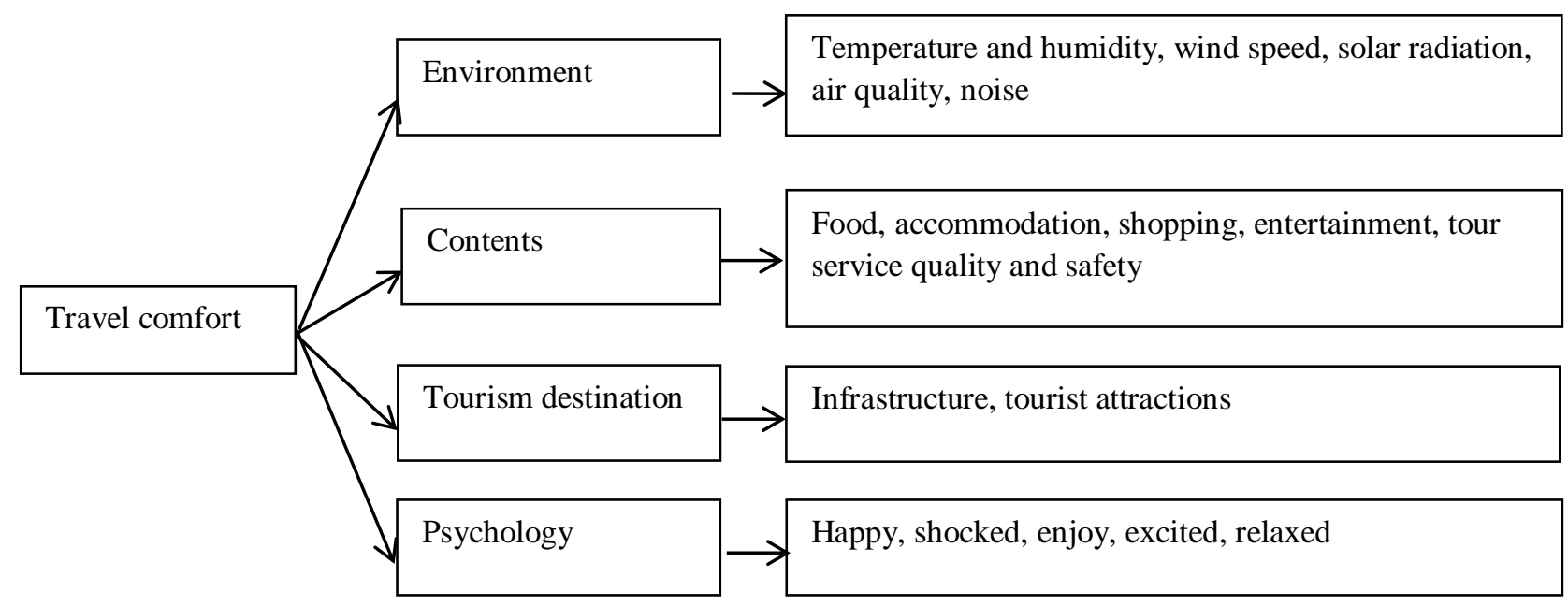

Figure 1: Types of travel comfort.

\subsection{Sampling and Procedure}

After literature analysis, this study summarizes the four dimensions that affect travel comfort: environment, content, travel destination and psychology. In order to understand the concept of 
travel comfort, the above four dimensions are used to ask the respondents whether they have ever had relevant travel experience, which will make them feel travel comfortable. Due to the limited literature, the authors aimed to use the interview method to enrich the theoretical data and understand the opinions of different types of people. When designing interview questions in this study, interviewees were asked the last question whether there are still other factors than the above four dimensions will make you feel comfortable traveling.

Before the formal interview, a pretest was conducted according to the interview manual. three students were chosen with rich tourism experience as the pretest subjects. The pretest is to enable the researchers to practice the interview techniques in accordance with the manual and modify the interview manual appropriately. The results of the pretest will not be included in the subsequent formal interviews.

In this study, the following three types of people were selected when selecting samples: (1) tourists with rich tourism experience; (2) experts and scholars in the field of tourism; (3) workers in the tourism industry. It is necessary to ask in advance whether it meets one of these three categories of people before conducting an interview. At least 3 interviewees were selected for each type of people to receive in-depth interviews. İnterviews ended when there is no new elements.

In order to obtain representative interviewees and experience of diversity, this study uses a three-stage sampling method to select interviewees. First, it used the convenience sampling method to recommend respondents who meet the above three groups of people through friends or friends who know researchers of this study. Then, using the snowball sampling method, the first-stage respondents recommended other people with the same experience to participate in the study. Finally, in order to make the sample meet the selected selection criteria, the purposive sampling method (Jiao et al., 2018) was used to solicit interviewees on travel associations website or at travel destinations. The purpose is to make the number of respondents in the six activities evenly distributed and cover various levels of experience.

The interview started on April 20, 2016 and ended on May 22. Considering the convenience of the respondent's time and place, most of the researchers conducted in-depth interviews with the respondent through the Internet, and some use face-to-face interviews, with each interview ranging from 25 to 40 minutes. The average interview time was about 35 minutes. In order to reduce error, the entire interview process is conducted by the researchers and recorded one by one. There are about 145 pages of collated verbatim manuscripts. A total of 9 in-depth interview samples were collected, all of which were representative types. Among them, 3 are tourists with rich experience in tourism; 3 are people engaged in tourism; 3 are experts in tourism. Among the respondents, there were 5 male (about 55\%) and 4 female (about 44\%).

\section{Results}

This study uses analyst triangulation to verify, by inviting experts with relevant experience in the tourism industry and a master's degree, and their master thesis as a judge for related parties to classify and name content. According to the reliability of content analysis, the ratio of classification agreement among different judges needs to be higher than 0.8 to be considered as reliable (Kassarjian, 1977). In this study, the reliability of the sub-categories classified into higher-order categories is 0.869 (20/23), Therefore, this study has good reliability.

This study finally combined the literature and in-depth interviews to divide travel comfort into two aspects of substance and psychology. The substantive aspects include 3 dimensions of environment, travel content, and tourist destinations, as well as 13 subdimensions. Psychological aspects include 2 dimensions of personal feelings and partnership, and 7 sub-dimensions. 


\subsection{Environment}

Temperature and Humidity - Tourism is mostly an outdoor activity. Therefore, the natural environment has a greater impact on the tourism process, which will directly affect the comfort of tourism. The environment-oriented temperature and humidity refer to the temperature and humidity in the overall environment of tourism. The appropriate temperature and appropriate humidity can make people feel comfortable;

\section{....For the climate, I personally don't like cold places. The tropical or subtropical areas are preferred, the temperature is moderate and neither too cold nor too hot. (P1-2) \\ ....In our work, there are many phenomena that are affected by temperature and humidity...So I think temperature and humidity will affect comfort (P6-3).}

Most tourists will choose to travel in the spring and autumn, because the temperature is more comfortable, and they don't need to carry too much clothing. Some people will choose to escape from the uncomfortable temperature of the location. For example, in the hot summer, tourists will want to travel by choosing a cool destination to achieve the purpose of summer escape; for example, in the cold winter, tourists choose a warm area to escape the cold. It is necessary for people with chronic diseases (such as rheumatoid arthritis, chronic tracheae, asthma, etc.) to avoid the scorching heat and cold in time.

Solar Radiation - The sun transmits energy outward in the form of electromagnetic waves, and the electromagnetic waves and particle streams emitted into the universe are called solar radiation. If there is bright sunshine during the journey, it will always make people feel better. But first of all, it must be appropriate solar radiation. If it is too strong, it will be counterproductive;

...I don't particularly like traveling in the sun, because I especially hate the process of applying sunscreen to my face and body, which is sticky and greasy. I still prefer the autumn climate. The sun is relatively mild and does not require sun protection. I can just leave without delay. I can put all my thoughts on the scenery around me (P9-6).

Especially for women who are care more about their skin; ...As a girl, the sun is completely a natural enemy. You always worry about getting tanned when you go out to play. Generally speaking, I don't like places where the sun is too scorching or too strong (P4-3).

Too strong solar radiation during the travel process will damage the skin. The strong solar radiation often makes people feel restless and eager to avoid. Therefore, it will also greatly affect the comfort of tourism.

Air quality - Judgment of air quality depends on the concentration of pollutants in the air, and its quality reflects the degree of air pollution. Tourists have different tourism purposes and attach different importance to air quality (Wang, 2019). From the current choice of tourist destinations, it can be seen that some tourists are beginning to pursue better air quality. Refreshing sky, high visibility and no pollutants that exceed the standard, which improve tourists 'mood and comfort;

... while enjoying the scenery on the edge of Lijiang. There are many trees on both sides, the air quality is good without too much dust, and I feel particularly comfortable. The environment, air quality and greening of a city or region are factors that affect the city's image (P3-5).

In recent years, there are also many tourists who pursue high-quality air and environment. More middle-aged tourists prefer places with high green vegetation coverage, high oxygen content and negative oxygen ion content. Tourists prefer the original way of 
tourism and hope to stay away from towns, factories and modern buildings. One of the more popular travel methods nowadays is health tourism, which allows the body to cultivate and adjust through travel;

...Isn' $t$ it very popular to go to places like Changshou Village and Changshou Town? Last year I accompanied my parents to Changshou Village, Bama, Guangxi to escape the summer heat for about a month. The air quality there is indeed very good, there are many tall trees, and no factories emit pollutants. Every morning in the mountains with my parents, exercise around. Breathing the fresh air feels as easy as rebirth (P7-5).

Precipitation - Precipitation is basically not loved by people during the travel process. Most tourists think that precipitation will affect their travel comfort. Excessive precipitation will make people feel annoying, sometimes it will affect the traffic and affect the ornamental value of scenic spots. Rainfall will require tourists to wear or bring rain gear. This will increase the burden on tourists and will affect the mood and quality of play;

...In terms of climate, I think I can accept it as long as it doesn't rain. If it rains, it will change all your itineraries and cause a big obstacle to travel. When it rains, the pictures taken will not look good (laughs). It will also affect your mood and play comfort (P1-2).

...It started to rain heavily, and it was very irritating. I don't like places where it rains. Especially for this kind of amusement facility, it will affect the mood of the whole person after a rain. Wearing a raincoat is inconvenient. There is simply no way to enjoy the fun (P92).

Noise - The characteristics of noise are noisy and harsh, which should not be found in certain environments. The noise not only prevents people from resting, studying and working normally, but also interferes with the sound people want to listen to (Zhang, 2019). In the process of traveling, noise pollution caused by transportation, whistle of vehicles, industrial noise, building construction, people talking loudly, etc. will often cause people irritable or endanger health.

...I don't like noisy environments. I feel noisy and noisy will affect the relaxed mood. If you say that if you go out to play, for example, the Songkran Festival, wherever you go, it is very lively, and everyone is very enthusiastic. That kind of environment can be noisy, but in a place where you should rest well, but it's noisy. I can't accept situation (P2 8-9).

Whether it is on the journey or after arriving at the destination, people want a quiet and suitable environment. During the journey, someone loudly clamors in public, and speaking loudly often affects the mood of tourists at the beginning.

...When I was in Bama Longevity Village, I chose to travel there because there was no noisy atmosphere and noise from the surrounding environment. Both my parents and I feel that I have stayed in the city for a long time and have been fed up with the feasting, noisy and disturbing social and natural environment. We should travel to a peaceful environment like Bama to change our mood and regulate our body. To escape the sub-healthy situation of contemporary people in modern cities (P7-7).

...On a small island in Similan Islands of Thailand, there are no hotels but tents. At night, there are only the sound of insects and waves. After all the noise is removed, what is left is the sound of nature, melodious and comfortable. Such an environment could not be better for the 
restoration of the body and mind (P5-11).

\subsection{Tour Content}

Diet - Diet is the basic guarantee for maintaining people's activities such as production and life. At any time, diet is very important, and it is also the same in the process of tourism. Not only life must also affect the comfort of tourists. Some tourists believe that the direct way to experience the culture of other countries is to taste local cuisine. Tourists also have their own hobbies for the diet in the process of traveling. Cost-effective regional and delicious food performance can increase the comfort of tourism;

....In terms of diet, I personally must take diet with regional characteristics, which will interest me. If you eat some fast food wherever you go, such as KFC or McDonald's, this kind of food is meaningless, because you can eat it everywhere. A special diet in a place will also make me happy and worthwhile (P1-9).

...It is also very happy to come to a tourist destination to have very delicious local food. The last time I went to Indonesia, although the climate was hotter, it made people feel more irritable, but the food there filled this shortcoming. I like the food there, such as the charcoal grilled satay skewers, authentic Indonesian fried rice, dirty duck meals, etc. They have local characteristics and taste very good (P5-6). ...Local food always attracts me, because I am a foodie. It was a hard journey. I might forget the stress of the original journey because of the delicious food at the destination. I will find local snacks, fruits, dinners and desserts, and I will be satisfied no matter what the taste is (P9-8).

Many tourists are mainly passionate about their diet and their hobbies, but some tourists are based on physical needs and cultural experience to talk about the factors of travel comfort. Aside from the taste, some tourists pay more attention to punctual meals and convenient meals;

...When it comes to eating and drinking, I am more concerned about whether I can eat on time because I think regular eating is necessary. I remember the last time I went to Sri Lanka, especially the distance between the attractions is relatively long, the driving time is very long, and there are no restaurants on the road. It is uncomfortable for people who don' $t$ want to break habits. (P7-8)

...After visiting the scenic spots with everyone, we were leaded to a local gourmet shop to taste the local food. Since everyone is Chinese, they have always spoken Mandarin to each other, and there is no atmosphere like in a foreign country. Many tourists generally feel that there is a difference in food, and they begin to feel that they are abroad. Only in this way can I integrate myself into the travel process more quickly (P4-5).

Accommodation - Accommodation is a relatively important part of the entire journey, because accommodation is a temporary residence for tourists on their journey, and different tourists have different understandings and requirements for accommodation. Tourists hope clean and tidy accommodation, at least to meet the basic needs of accommodation and rest. Of course, there are also some places have higher requirements for accommodation. I hope that they have basic functions and convenient transportation, good service, and it is best to meet their own preferences. The whole atmosphere is warmer and homier;

...I don't have much requirements for accommodation. Basic facilities

will satisfy me. Convenience is the most important. It is better if the 
front desk can book local transportation and travel advice (P1-10).

...Accommodation is vital, first of all, it must be clean and hygienic, at least the basic facilities must be complete. Also, the transportation should be convenient in the place of accommodation. It is best to be closer to public transportation. Which is convenient and cost-effective. There is no need to make the accommodation luxury, which is meaningless. But I still hope that the place to live is cozier, because I often go out on business trips, I still miss home (P6-9).

Many tourists now choose to book accommodation such as hotels or homestays through the Internet and many software. In this way, you can make a reservation in advance according to your own requirements for accommodation, because you can refer to the screening conditions of the website when booking, and browsing the pictures and texts has a general sensory experience of the accommodation conditions, which is very convenient and easy to meet. Choose accommodation with different themes according to your preferences. However, what comes with convenience is that the propaganda and reality should be basically consistent. If the propaganda is false, it does not conform to the real thing and it will also cause tourists discomfort.

...Last year, my girlfriend and I went to Korea to play together. We had a discussion from the beginning. We wanted to live in a selfoperated homestay with the theme of hello kitty in the central area. Because there was promotion on many websites before, it looked very beautiful and very exciting. After I got there, the boss was also very enthusiastic. The actual situation of the room was the same as the pictures posted on the Internet. Then I thought it was worth it, and I looked forward to the next trip to Korea (P9-13).

Shopping - People's incomes increase with economy development. Meanwhile, the desire for shopping increases which profoundly influence travel comfort. Under the different divisions of tourist destinations, it can be found that some tourists specifically want to go shopping, and shopping is the ultimate goal during tourism. This type of tourist has a relatively high level of shopping malls, discounts, convenience and infrastructure for arrival. High demands. Other tourists who want to experience local shopping will pay more attention to local customs and atmosphere;

...For shopping, I hope I can buy things with local characteristics. If it is a large shopping mall, of course, the lower the discount, the better. (P6-12)

...I might prefer to go shopping in a metropolis, because there is air conditioner. Last time I went to Malaysia to shop in the mall on the Petronas Twin Towers in Kuala Lumpur. There were a lot of things and brands. Even if I was tired of shopping, there were many places to eat. I would prefer to go to such places. Shopping in such places is more comfortable (P3-7).

...There will be some tourists going out to travel, but they only go shopping. Some of them are bought for themselves and their families, and a large part of them are purchased by purchasing agents. A good shopping environment and the discounts and tax rebates offered by local policies to shoppers are all factors that affect the comfort of such tourists. A tourist route like Hong Kong opened by our travel agency is that many tourists think that the destination is to go shopping, and then choose a group to save the trouble in the middle (P6-15).

Contrary to this type of tourists, they prefer local more traditional shopping venues, such 
as some traditional markets or night markets. They do not mind whether the shopping venue is modern, whether it has a full range of brands, and whether there are sound supporting facilities. They just want to experience local customs. I hope to buy goods with rich local characteristics and use it as a souvenir or take it home;

...I hope I can buy things with local characteristics. Like last time I went to India and bought local spices, it is very unique. When I go to Sri Lanka, I will buy some local black tea, some for myself, and some as gifts (P1-15).

...For example, if you go to a place with different culture, bring some souvenirs to your family and friends, such as something rich in local cultural characteristics and special local materials. When I went to Sanya, I bought a hat made of palm bark. Many straw hats or hats made of bamboo are made of bamboo or other things. They are basically inseparable, but now the palm tree I still keep the leather hat. It has local characteristics, so I think it's great (P2-34).

...Go to Southeast Asian countries and you will find that it is really popular to go to night markets at night, perhaps because the national online shopping method is not yet mature. In the night market, you will see a lot of local crafts, and the price is also very suitable. Experiencing the local culture while shopping is fabulous (P8-17).

Entertainment - Tourism is a type of entertainment. The entertainment factors mentioned in this study refer to the entertainment methods, entertainment items, and entertainment venues included in the travel process. Tourists experience differently and pay more attention to the comfort of entertainment during the journey.

... When I go to a place, I will experience the local bar, local nightlife and wine culture with my friends, because after all, I am a young man. If there is such a place in the local area, I will be happy and satisfied (P1-16).

...At the destination, there will be young people asking us to take them alone to the more lively or young fashion street after the end of the day's itinerary, and some like to go to the more famous nightclubs and bars in the local area Live the nightlife that belongs to young people (P4-11).

At that time, when taking the Dubai line, people are rich. Many people will choose to take a bet at the local area, which is regarded as an experience. Some brave young people will go to Dubai's skydiving. The stimulating, thrilling feeling will make them feel comfortable. (P418)

When I was in Phuket, the scenery was very beautiful, but my favorite, the most memorable is the water entertainment projects and entertainment facilities, very exciting, very fun. For example, what kind of paragliding, banana boat, snorkeling and depth are very exciting and very cool (P8-21).

Itinerary Customization - With the development of the economy, the product-oriented economic model has shifted to service-oriented. Focusing on customers, products are required to meet customer needs, and products are produced and customized according to customer needs. The same is true during the travel process. Customers also hope to customize their itinerary according to their actual situation and needs. Tourists believe that tailoring the itinerary according to their own specific conditions can certainly affect comfort, because they know what they need and what kind of itinerary and arrangement will make them feel comfortable; 
...The choice between the attractions will allow everyone to adapt first, and then come to the plateau to visit the attractions at lower altitudes first, and put those attractions that need to be turned higher in the mountains behind the itinerary, so that there is more time To adapt to the discomfort caused by the difference in altitude, reducing discomfort will increase travel comfort. I hope that more travel agencies or tourism agencies will be able to give more flexible travel planning and customizing methods in the future (P7-14).

...Because it is a honeymoon trip, it is quite different from the general travel itinerary. Our company has changed its model from this aspect. We provide customized itinerary services for honeymooners, and make it according to their preferences, including travel routes and hotels. For those who like sightseeing, arrange for sightseeing, and for those who like to stay in the hotel, arrange indoor activities. It can meet the comfort of different newcomers, so this model is good based on customer feedback (P6-21).

Customized transportation can make the journey more scientific and comfortable. Customizing itinerary according to your needs, preferences and actual situation can greatly improve the comfort of tourists and reduce customer dissatisfaction. Previous researchers did not systematically study this factor, and this content is one of the findings of this article;

...It is best to have exclusive services, such as chartered cars. The cost maybe higher than public transportation, but it can bring more convenience (P2-23).

...A high-quality journey, I think it can be customized, according to their preferences and physical conditions to customize the journey. Just like the last time we went to Tibet as a group. Because they are a big family, because some elders are afraid that their physical adaptability is relatively poor. If they fly directly by plane, there will be too much altitude difference, and it is difficult to adapt to the problem of oxygen content in a short time, so that they will have altitude sickness. If altitude sickness occurs just after traveling, it will greatly affect the mood and the comfort of traveling. Therefore, when ordering this journey, I deliberately chose the train, because it takes a long time to ride, so I chose the carriage with the best conditions ( $\mathrm{P} 7-$ $14)$.

\subsection{Tourist Destination}

Infrastructure - The most intuitive thing about arriving at a tourist destination is the local infrastructure of the tourist destination. The road conditions and the convenience and comfort of transportation during the journey to the destination are the first to be experienced and can be directly evaluated. Many tourists prefer different modes of transportation, and there are more modes of transportation to choose from when the destination has a good transportation infrastructure. Perfect road infrastructure can reduce traffic jams and increase the comfort of tourists;

...After arriving at the destination, it mainly depends on whether the city is clean and whether you like the atmosphere. Every place is different, it must be a clean place, which will make people feel comfortable (P1-3).

...For tourist destinations, I personally prefer to have more convenient transportation, and transportation is quite important. If you can't even get the traffic, it will definitely be a big obstacle to travel (P5-9). 
...The local basic facilities of the tourist destination can meet the basic life, but the transportation must meet the basic needs of tourists. You can charter a car to go back and forth between the attractions, and that's it. The most important thing is that the infrastructure can satisfy tourists to move between attractions (P6-11).

...There is also the convenient transportation. I will only consider going there if there are direct flights between countries or between distant attractions. This is also one of the factors that affect my choice of destination (P7-16).

...I think it must be a clean and beautiful environment that makes people feel comfortable. When I went to the United States, the streets there were very clean, the ground was covered with asphalt roads, and the lanes drawn on the road were very clear. Unlike domestic roads and streets, which are messy and messy, there is also a lot of dust on the roads, except for the rain (P5-31).

Tourist Attractions - Tourist attractions in tourist destinations are undoubtedly the focus of tourists' experience. Different tourists have different requirements and expectations for attractions, and different types and preferences of attractions. Some tourists are fond of cultural attractions, for example, they like to go to local museums, folk villages, church buildings, etc.; while some tourists like natural landscapes very much, such as the Grand Canyon, primitive forests, river waterfalls. Being able to sniff the expectations and preferences of tourists will of course add points to the comfort of travel;

...I like scenic spots that reflect the local culture and history. For example, in Tibet last time, I was really shocked by the culture of Tibetan Buddhism. People's pious worship and Buddhist cultural beliefs make you sigh. I like sights that reflect local culture and history. For example, last time in Tibet, I was really shocked by the culture of Tibetan Buddhism. People's pious worship and Buddhist cultural beliefs make you sigh, and the Potala Palace is also a cultural precipitation. The buildings in the cultural background look very charming. I like to take my children during the holidays to see the different cultural customs and architectural styles expressed by different regional characteristics (P7-21).

...I have been to scenic tours and cultural tours, but I prefer cultural tours. For example, I have always liked Dunhuang because of the history and culture there. I want to see what kind of history and culture let such beautiful grottoes and murals continue to this day. Even if the environment in Dunhuang is relatively harsh, relatively dry and dusty, and the food is not tasty, but I decided to go for such a beautiful cultural attraction. Facts have proved that this trip is worthwhile (P3-28).

...If let me choose. I may choose some places with a long history, famous culture, but not so popular. Recently, I want to go to places in South America, such as places like Machu Picchu in Peru. It feels very special. Because the culture is very different from China, I want to experience it because of the difference (P8-25).

...In terms of tourist destinations, the first thing I want is the type of scenery I like. I like those European-style buildings, churches, green squares. I don't like ruins, so I don't want to go to places like Angkor Wat in Cambodia (P3-29).

Local Residents - Local residents are an important part of tourist destinations and belong 
to the cultural landscape, which directly or indirectly affect the comfort of tourists. The quality, character, hospitality and manners of the local residents are miniatures of the culture and customs of the tourist destination. The attitude of residents of tourist destinations towards tourists is an important reference factor for whether tourists choose this trip or whether they choose this destination again. The hospitable local residents will make the tourists feel at home, and give the tourists a sense of belonging, allowing them to integrate into the local culture and scenery more quickly. A country and a nation dominated by tourism should ot have ethnic conflicts and state discrimination. Another aspect is the locals' awareness of the protecting local tourism resources and the importance they attach to the local tourism environment and cultural relics. A good sense of protection can increase the value of tourists' appreciation of this trip;

...Local people, I think it is the most important part. For example, if you go to a place and fooled by locals, you will be in mood immediately. And won' $t$ come to the place again (P1-20).

...Compare to air quality, environment, and scenic spots, I think friendly atmosphere is more important. I would choose more friendly destinations (P2-11).

...For the residents of the destination, it must not be offensive, at least not anti-China. I would not choose to go to those places until situations improvement (P3-23).

...When I was in Sri Lanka last time, I often saw the local residents on the roadside with a smile on their faces and greeted you sincerely. In the indifferent human society, such simple folk customs will make you feel warm and make your journey more comfortable (P8-27).

\subsection{Personal Feelings}

Heartbeat - Beautiful and unforgettable scenery of the tourist destination will make you feel excited, many tourists are persuaded and intoxicated by the local natural scenery and cultural environment. Inner feelings of tourists, for example, this trip itself can make tourists feel comfortable;

...I prefer monuments and ruins with historical deposits, as well as unsolved mysteries like pyramids. I would be more interested in these. In addition, I am also interested in some museums, science and technology museums, and art galleries. Such places make me touched and excited (P1-26).

...There are also psychological shocks, such as being infected by some local beliefs and some atmosphere. When you are in Tibet, you will see many people knocking one step at a time because of their faith. Such scenes and atmosphere will make people feel shocked, and their hearts can't be calm for a long time (P3-18).

...If the local government of the tourist destination has certain discounts for foreign tourists, such as opening a VIP channel for foreigners, fast-track channels and the like. I feel that this country attaches great importance to foreign tourists. If they are psychologically satisfied, they will like that country more, and it will increase the comfort during the tour (P1-35).

...It's shocking at first sight. When I was in Australia last time, as an inland city I grew up, I have never seen churches, lighthouses and coastal dams before. After seeing it, I feel very fresh and like it. I just feel excited when I see something that is not usually easy to see. I think this trip is worthwhile (P9-23). 
Adventure Challenge - Some tourists fancy adventurous challenges and prefer adventurous destinations. If the personal hobby can be satisfied during travel, they feel comfortable. Previous researchers have not conducted a systematic study on this factor, and after in-depth interviews discovered this factor, this content is one of the findings of this study;

...In terms of personal feelings, I personally like exciting projects and taking risks. Some stimuli with difficulty will always attract me. Last time I went to New Zealand, I didn't care about the others. I just rushed to skydive. As long as there are such stimulus items, I think this tour is comfortable. Jumping in such a beautiful place, my heart is really satisfied (P3-77).

...I really like recreational projects at sea, like sailing, kayaking, paragliding. I feel that comfortable travel excitement and adventurous activities are indispensable. Having met my challenge mentality, I feel comfortable when traveling (P9-34).

Sense of Security - Security are mentioned frequently by the interviewees. The security needs are the basic requirements and of course the foundation of comfort. Safety is the principal thing when it comes to tourism activities. Safety is the most important for tourist when choosing destination;

...Another particularly important issue is safety. The reason I have always rejected going to India is because of the rapes I see every day, various murders, the bad habits of the locals, and all kinds of terrible religious culture. I felt that my life was threatened, so I would not want to go to that kind of place. Although Indian culture is still very attractive to me, I might consider when culture overcomes the issue of security. In fact, safety is still the most fundamental issue (P4-36).

...Safety is a very important factor. Every place and country must have different cultures and scenery. Before going, we must consider the local safety level. If you were to go to Iraq or Somalia, you would definitely not dare to go. The question of security is a question that determines whether I go or not (P7-34).

...For example, is the entire political environment in the destination country safe? There are still wars in places like Iraq, and antimainland demonstrations in Hong Kong. Basic personal safety is not guaranteed, let alone the comfort of travel. The entire transportation, clothing, food, housing, transportation, travel, shopping, etc. must be basically safe (P2-41).

Relax - Relaxation should be what most tourists are after, and it is one of the purposes of their tourism activities. Beautiful and comfortable scenery, ample time schedule allows tourists to do what they want to do, which can make tourists feel relaxed;

...I think we can't forget the essence of tourism, just to relax tired body and mind. Therefore, the whole journey cannot be made too stressful. In order to catch up with the schedule, the tourist attractions are lined up very full, so that I will lose sight of the other. I should be very relaxed, but I am very tired. This will not feel comfortable. I think the most important thing about traveling is psychological and physical relaxation $(\mathrm{P} 1-45)$.

...The travel process is to stop and stop, feel the beauty while playing, forget the troubles of work and study. Let your body relax, you don' $t$ have to get up very early, and you don' $t$ need to be tired every day. The beautiful scenery makes the heart more fulfilling, more relaxed 
and clearer (P7-39).

Easy Freehand - First of all, when riding a vehicle, tourists should choose comfortable shoes to avoid uncomfortable feet. If they are flying for a long time and the air conditioner temperature is low, then the flip-flops won't be a good choice. Tourists' feet will be cold and uncomfortable. When traveling abroad, they'd better not bring decorations, such as necklaces, bracelets, and large earrings, which is easy to lose and may increase travel burden. In general, the travel process should be as concise as possible and not too complicated. Easy and simple dressing and choice will make you feel the comfort of travel;

...When I traveled and took an airplane last time, I deliberately changed into double flip flops, thinking that my feet would be more comfortable and my legs would not be swollen easily. However, due to the long flight time, the feet were exposed and it was cold, and finally had to ask the stewardess to cover it with a blanket. I think shoes must be comfortable, suitable for the occasion and specific purpose. Only then can the journey feel comfortable (P3-55).

...There is also the aspect of dressing, simple and casual, not too complicated. Give up some excessive accessories when traveling, such as heavy necklaces, exaggerated earrings and so on. This reduces the burden and avoids loss. What you need to travel light to the official tour (P7-42).

...In terms of clothing, I like to buy some local characteristics and clothes that are in line with the local climate. For example, wearing some loose and comfortable long skirts at the beach, and going to the ethnic minorities to wear their national clothes can also be regarded as an experience (P9-47).

\subsection{Partnership}

Like-minded - On the psychological level, the interviewee mentioned they prefer more people in the same field. They hope that it is best to go on a trip with friends. There is already a foundation of friendship among friends. No break-in period is needed. Everyone will play and have fun together, and travel will not be boring. Most respondents even felt that as long as they were with like-minded people, other influencing factors became less important. Harmonious partnership will bring more comfort to tourism. Even those who travel alone hope to get acquainted with their temperament and temperament partners. Partners with common interests, hobbies and values will make the journey smoother. Everyone will help each other enjoy the scenery together and overcome the difficulties. The entire travel process will not feel hard and tired;

...If you are traveling, I think it is very important that your friends are with you, who you choose to go with. It is very important to be together, and you must find someone who is co-produced with yourself and has similar values. Everyone should plan together and share some things together. This is important (P1-64).

...Friends are very important. If you travel to a place, you can experience new things together with people who have common hobbies, which is more casual. If you have a lot of things with elders or people you don' $t$ know, you will have restrictions on traveling and you will not be so comfortable (P4-39).

...The important thing is who to go with, in fact, it is not a far-off place to be considered a tourist. I might just play on the outskirts of the city, and I will also feel very happy, as long as I am with my favorite friends. As long as the friend is right, I will not be so picky 
about the destination, even if it is not so beautiful, I will not complain (P6-66).

...Hang out with friends, everyone knows each other, there will be no conflicts, and there will be no quarrels. If there are too many quarrels during the journey, it will affect the mood and affect the comfort (P748).

...My dream is to have my free time, and then travel with my friends and girlfriends. Everyone likes the same things, so there is no need to evacuate whom. Everyone knows each other well and gets along very casually and relaxed (P9-41).

Number of Peers - In terms of partnership, some respondents also detailed the number of peers they considered to be more comfortable and reasonable and the lowest cost. Even if it is a reliable partner, the number of people should not be too large. Generally, the number of comfortable and reasonable peers is $2-4$. If the number is too large, it will also bring uncomfortable feeling during the travel;

...As far as I am concerned, I like to travel together with two people. I feel uncomfortable when there are more people. Two people are just right. Someone is company without too noisy. The two people are out there to enhance the relationship (P2-47).

...It's impossible to eat, drink, play, and shop all by myself. I usually choose two or three friends to go out when traveling. I don't choose four people to go out. It's because two people can play with each other. As for the three people, it's impossible to throw one person out. If there are four people, they will play separately. Then there is no fun of traveling with companions (P5-39).

...If you plan to travel, I will usually meet about 3 friends, usually singular. In the planning stage, everyone can divide the work, book a hotel, book a flight, and do strategies. You can divide the work, and it will not be too hard. When there are disagreements during the trip, three people may vote for it. I think 3 people are the most convenient. (P8-35)

...Traveling is of course the most reasonable for 4 people. Whether it is a taxi or charter and accommodation during the journey, it is the most cost-effective for 4 people. The combination of 4 people is the lowest in travel cost (P3-68).

\section{Conclusion, Implications and Limitations}

This study first sorted and reviewed the literature related to travel comfort, then combined with in-depth interviews, and finally conceptualized the term "travel comfort" as: in tourism activities, tourists make evaluations of the tourism environment, the content of the itinerary and the destination, at the same time get satisfaction at the individual's physical and psychological level, and achieve the ideal partnership. This concept is more comprehensive and specific than previous studies such as Li and Tang (2013) and Ye et al. (2012).

Because past research has not fully explored the connotation of travel comfort. Therefore, this study selected individuals with rich experience in tourism, tourism industry practitioners and tourism-related scholars to conduct individual in-depth interviews, and then through a rigorous content analysis method. It is intended to obtain the concept and connotation of travel comfort.

After analyzing the content, this study classified 20 sources of travel comfort. And it can be divided into five aspects from the physical and psychological aspects, namely: environment, tour content, tourist destination, personal feelings and partnership. All source 
components come from environmental, location, personal and partner factors. It can be seen that there is an interactive relationship among people, tourism, and places.

Travel comfort is an important part of comfort. However, at present, some scholars simply describe and define travel comfort based on the factors of their own research and design to study the influence of climate on the number of tourists. Some scholars also study the relationship between tourist destinations and changes in tourists, and only use scenic spots as an influencing factor for tourists' comfort. This research clarifies and unifies the concept and connotation of travel comfort, which is helpful to the comprehensive theoretical development of comfort related fields. In the future, scholars can deeply explore the causal relationship between factors that affect travel comfort.

In the travel comfort environment, it includes five sub-projects: temperature and humidity, solar radiation, air quality, precipitation, and noise. In the meaning of management, relevant departments are required to be able to supervise the air quality of tourism-related places, reduce noise, bring a comfortable tourism environment for tourists, and improve the comfort during tourism. Tourists, as consumers, should pay attention to the seasonal climate of the destination when improving their own comfort and evaluating travel comfort, to see if temperature, humidity, solar radiation, precipitation, etc. are suitable for tourism.

The content of the journey in the tour contains elements: food, accommodation, shopping, entertainment and journey customization. Tourism related departments should vigorously supervise food safety during tourism, improve the accommodation conditions of tourists, and develop entertainment projects to meet the needs and hobbies of different tourists. The tourism industry should choose to provide tourists with distinctive food and drink locations as much as possible to provide meals on time, cooperate with tourism related departments to choose better accommodation conditions, and introduce better shopping locations and shopping guides for tourists. The most important thing is that the tourism industry should provide tailored journeys for different tourists' needs to meet tourists with different conditions and needs. Tourists should have their own standards for their own safety and accommodation to judge their comfort.

The relevant departments of tourist destinations should vigorously strengthen the construction of infrastructure and the development of tourist attractions, improve the supporting facilities of tourist destinations, improve the quality and awareness of residents in tourist destinations, and attract more tourists to carry out tourism activities. Tourism should also recommend more valuable attractions for tourists to coordinate the opinions and feelings of tourists and local residents. Tourists should also respect the customs of local residents, understand each other, and jointly create a comfortable tourism environment.

Personal feelings often make people feel thrilled, adventurous, challenging, safe, relaxed, and freehand. Since it is a personal feeling, tourists should cooperate with relevant departments and the tourism industry in the process of tourism to enhance their comfortable personal feelings. The partnership aspect includes the like-mindedness and the number of peers. The choice of the traveler 's peers should try to choose to travel with like-minded friends who share common interests or have the same value. This is closely related to the comfort of tourists during the travel process. Another thing is that the number of people in the industry can only get comfortable feeling if they are matched with the right number of people.

First of all, this study only uses qualitative research and focuses on the concept and connotation of travel comfort, so lacking quantitative statistical data and related analysis. Therefore, it is suggested that future research can extract the relevant items from the concept of travel comfort, develop a travel comfort scale, to measure and evaluate travel comfort. Secondly, researchers purposive selected Chinese people for interviews in this study, therefore, the applicability of the research results has limitations. It is suggested that future research can choose people from different countries to see whether travel comfort has different components and connotations to deeply enrich travel comfort and make the research 
results more applicable. Finally, future research can be conducted in the form of focus group interviews to encourage respondents' extending ideas and extract of new factors.

\section{References}

Dai, Y.-Y. (2018). Segmenting low-carbon tourists by Low-Carbon Travel Scale. In Maki K. Habib (ed.), Handbook of Research on the Evolution of IT and the Rise of E-Society, Chapter 23, pp. 508-525. Hershey, PA, USA: IGI Global.

Fang, F. (2008). Research on the relationship between tourist destination image and behavioral intention based on tourist perception-Taking West Lake scenic area as an example. Master thesis of Zhejiang University, Hangzhou, Zhejiang, China.

Hua, X., Wang, L., and Tang, D. (2014). The impact of climate comfort on tourism-Taking Nanjing as an example. Statistics and Decision, 30(3), 119-122.

Huang, L.-Y. (2014). Research on conceptualization and types of food addiction. Master thesis of Providence University. Taichung, Taiwan.

Jiao, Y., Hou, J., and Liang, Y. (2018). Analysis and research on tourism climate conditions and travel comfort characteristics of Jincheng City. Environmental Science and Management, 43(5), 109-112.

Kassarjian, H.H. (1977). Content analysis in consumer research. Journal of Consumer Research. 4(1) 8-18.

Li, H. and Tang, C. (2013). Research on the evaluation system of scenic travel comfort under the low-carbon concept. Journal of Xinyang Normal University (Natural Science Edition), 26(4), 73-76.

Lin, W.-R. (2008). Conceptualization and scale development of adventure and recreational challenges. Master thesis of National Chiayi University. Chiayi, Taiwan.

Liu, M., Wang, S., Ding, S., Lu, P., and Liu, Y. (2019). The impact of the "temporary" tourists' spatial and temporal distribution on travel comfort-Taking the Wangshi Garden as an example. Chinese Landscape Architecture, 35(9), 129-134 .

Liu, Y., Lu, Z., and Chen, X. (2019). Construction and application of climate comfort model for summer tourism. Journal of Sun Yat-Sen University (Natural Science Edition), 58(3), 22-31.

Ma, F. (2019). Correlation analysis of Jiuzhaigou tourism climate comfort degree within the year and passenger flow. Tea in Fujian, 41(7), 112-114.

Peng, J., and Wang, Y. (2014). Spatial relationship between the reality of spring and travel comfort_- Taking Wentang Hot Spring in Yichun as an example. Tourism Forum, 7(6), $38-42$.

Qin, J., Zhang, P., and Chen, X. (2014). Study on the ecological environment conditions and comfort of summer vacation tourism in Ya'an area. China Population, Resources and Environment, 26(S1), 297-300.

Wang, G., Qian, L., Chen, T., Yang, X., Xu, Z., and Zhu, W. (2015). Evaluation of tourism environment comfort and its spatial and temporal differentiation-Taking Hangzhou West Lake as an example. Acta Ecologica Sinica, 35(7), 2206-2216.

Wang, L. (2018). Echo state network optimization design and application research. Doctoral thesis of Beijing University of Technology. Beijing, China.

WTTC (2017). Travel and tourism: Economic impact 2017 Nepal. London, United Kingdom: World Travel and Tourism Council (WTTC).

Yang, L. (2008). Research on the establishment of evaluation index system and evaluation method of tourism destination comfort degree. Review of Economic and Management, 15(5), 68-73.

Yang, X. (2015). Hangzhou tourism environment comfort evaluation and analysis of influencing factors. Master thesis of Zhejiang University of Technology, Hangzhou, Zhejiang, China. 
Ye, X., Wei, P., and Qin, R. (2012). An analysis of travel comfort in Bama County of Guangxi in recent ten years. Meteorological Research and Application, 33(s2), 84-85, 89.

Zhang, L. (2019). Short-term effects of PM2.5 and O3 pollution on acute nasopharyngitis in 4 cities of Guangdong, China. Master thesis of Guangdong Pharmaceutical University. Guangzhou, Guangdong, China.

Zhou, H., Sun, P., and Geng, W. (2012). Tourism climate resources and comfort analysis of Weihai City. Shandong Meteorology, 32(3), 26-27.

\section{Acknowledgement}

This study is funded by Humanities and Social Science Fund Project (Grant No: R201709) and Doctoral Research Fund of Shandong Jiaotong University.

\section{Author Biography}

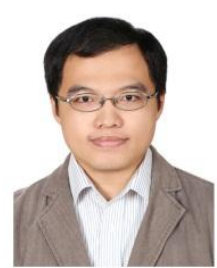

You-Yu Dai is an Associate Professor from the Department of Tourism Management at the International Business School of Shandong Jiaotong University, China. He obtained his PhD from the Graduate Institute of Recreation, Tourism and Hospitality Management, National Chiayi University, Taiwan in 2015. His research interests are tourism management, tourism marketing, tourist behaviour, cruise tourism, and low-carbon tourism. He has published more than 50 academic papers.

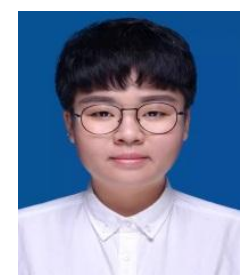

Xiuyuan Zhang is a Master of Business Administration. She obtained her M.B.A. degree from the China-ASEAN International College of Dhurakij Pundit University, Thailand in 2016. Her research interests are tourism marketing.

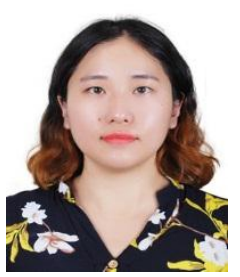

Xiaonan Feng is a Lecturer from Department of Tourism Management at the International Business School of Shandong Jiaotong University, China. She obtained her Master degree from TEFL, Swansea University, UK in 2015. Her research interests are tourism English, cruise English teaching, cruise tourism and intercultural communication. She has published 6 academic paper 